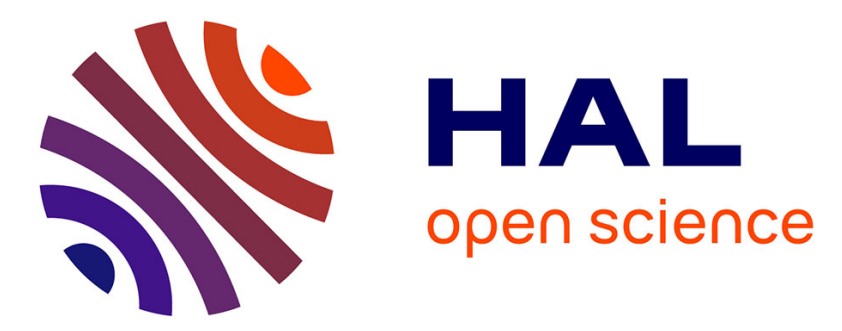

\title{
Increase of Stability Margin in Embedded DC Electric Grid with Superconducting Stabilizer
}

\author{
Guan Bin Huang, Bruno Douine, Kévin Berger, Gaëtan Didier, Isabelle \\ Schwenker, Jean Lévêque
}

\section{- To cite this version:}

Guan Bin Huang, Bruno Douine, Kévin Berger, Gaëtan Didier, Isabelle Schwenker, et al.. Increase of Stability Margin in Embedded DC Electric Grid with Superconducting Stabilizer. IEEE Transactions on Applied Superconductivity, 2016, 26 (4), pp.5000304. 10.1109/TASC.2016.2543963 . hal01290382

\section{HAL Id: hal-01290382 \\ https://hal.science/hal-01290382}

Submitted on 18 Mar 2016

HAL is a multi-disciplinary open access archive for the deposit and dissemination of scientific research documents, whether they are published or not. The documents may come from teaching and research institutions in France or abroad, or from public or private research centers.
L'archive ouverte pluridisciplinaire HAL, est destinée au dépôt et à la diffusion de documents scientifiques de niveau recherche, publiés ou non, émanant des établissements d'enseignement et de recherche français ou étrangers, des laboratoires publics ou privés. 


\title{
Increase of Stability Margin in Embedded DC Electric Grid with Superconducting Stabilizer
}

\author{
Guan Bin Huang, Bruno Douine, Kévin Berger, Gaetan Didier, Isabelle Schwenker, and Jean Lévêque
}

\begin{abstract}
Embedded electric grids are constantly subject to problems of stability. Some responses can be done with the help of Resistive Superconducting Fault Current Limiters (RSFCL). In this paper, we propose a new system named Superconducting Stabilizer (SS) in order to stabilize DC grid. The SS uses the losses created by the $\mathrm{AC}$ and $\mathrm{DC}$ components of the current to increase the stability margin in DC electric grid. For DC electric grid, in stable state, only the DC current component exists. If the load increases beyond a threshold limit, the DC electric grid becomes unstable and the current contains $\mathrm{AC}+$ DC components. The SS has very low losses in superconducting state and they can be considered as negligible in comparison with other losses in DC grid. In case of unstable state, the AC component of the current induces losses in the SS. It will be theoretically shown that increasing of the losses in the SS can stabilize the DC grid with efficiency. In this paper, the measurements of the critical current $I_{C}$ and the AC $+\mathrm{DC}$ losses of SS are reported. A comparison between a short length tape, and two superconducting non-inductive coils has been made. The tape used in the experiments is a DI-BSCCO tape. One non-inductive coil is wounded on an aluminium plate and the other one, on a wooden plate. In this latter, the turns are free to move and also, better cooled by liquid Nitrogen. Similar values of losses per meter have been measured for the three samples. The only and important observed difference is the maximal current which leads to the transition of the non-inductive coils. It can be explained by the cooling efficiency of the designed coils. These experimental results are useful to design $\mathrm{SS}$ in the future.
\end{abstract}

Index Terms-DC electric grid, stability margin, superconducting stabilizer, superconducting tape, losses.

\section{INTRODUCTION}

$\mathbf{T}$ HE stability margin is very important in all electrical systems. For this reason, people always try to find the optimal stability condition to maintain the system stable.

To solve the problems of stability, there are many theoretical methods to study dynamic electrical systems and also many devices called stabilizer to be installed in the electrical system. The traditional stabilizer work well with the small rated power system, but for a big rated power system, the mass and volume of traditional stabilizer become heavy [1]. Especially for an Aircraft Electric Power System, the mass is mostly a decisive criterion in the choice of avionics technologies. The new system called Superconducting Stabilizer (SS) in this paper can stabilize a DC grid and also be able to reduce the mass of such devices. The usual architecture of autonomous DC electric grid is represented in Fig. 1. An electrical alternative generator provides electric power to an $\mathrm{AC} / \mathrm{DC}$ converter.

G.B. Huang, B. Douine, K. Berger, G. Didier, I. Schwenker, and J. Lévêque are with the Groupe de Recherche en Electrotechnique et Electronique de Nancy, University of Lorraine, France.

Manuscript received September XX, 2015; revised December XX, 2015.

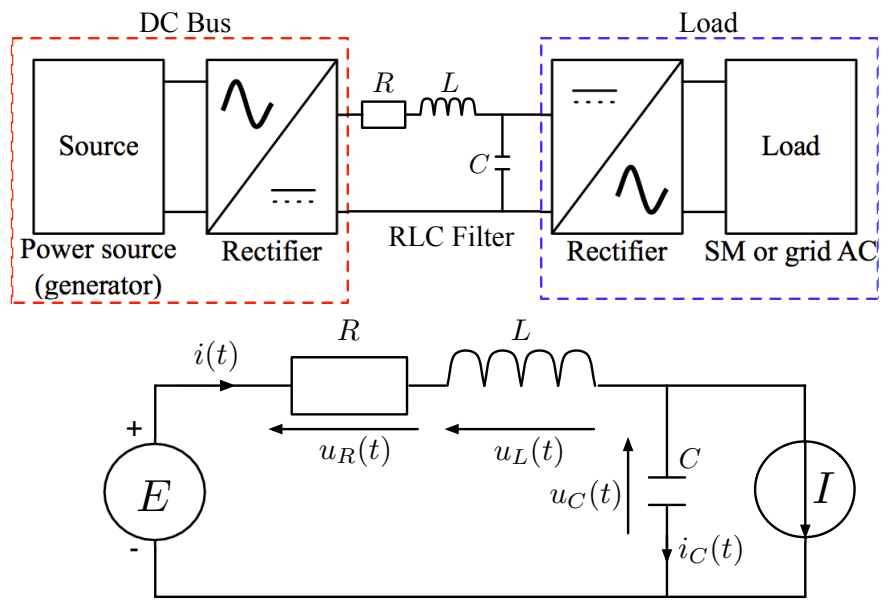

Fig. 1. DC electric grid architecture and equivalent circuit.

An $L C$ filter is located after the rectifier in order to have a perfectly smooth constant DC output voltage. In fact, the architecture of the DC grid mainly consists of three main blocks: DC Bus, $L C$ filter and a load (Fig. 1). In addition, $R$ characterizes the entire resistance of the grid, including the resistance of the stabilizer.

In our study we can consider that:

- the voltage of the DC bus is constant,

- the voltage drops across $R$ and $L$ are negligible,

- the load is modelled by a perfect current supply $I$.

So we can represent the DC electric grid by an equivalent circuit (Fig. 1). The stability of this DC system can be studied by Lyapunov Stability Theory [2]. The instantaneous dissipated power of the load is $p(t)$. Firstly, two equations can be written by Kirchhoff's voltage law and Kirchhoff's current law as:

$$
\left\{\begin{array}{l}
\frac{d i(t)}{d t}=-\frac{R \cdot i(t)}{L}-\frac{u_{c}(t)}{L}+\frac{E}{L} \\
\frac{d u_{c}(t)}{d t}=-\frac{i(t)}{C}-\frac{p(t)}{C \cdot u_{c}(t)}
\end{array}\right.
$$

The equation of state can be written as:

$$
\left\{\begin{array}{r}
\dot{x}=f(x) \\
x=\left[i, u_{c}\right]
\end{array}\right.
$$

We can now express the matrix form of Lyapunov Stability Theory as:

$$
\dot{x}=[A] \cdot x+[B]
$$

The matrix $[A]$ can be resolved as: 


$$
[A]=\frac{\partial \dot{x}}{\partial x}=\frac{f}{\partial x}=\left[\begin{array}{cc}
-\frac{R}{L} & -\frac{1}{L} \\
\frac{1}{C} & \frac{P}{C \cdot u_{c}^{2}}
\end{array}\right]
$$

We need to study the eigenvalues $\lambda$ of matrix [A] by using (5).

$$
\begin{gathered}
\operatorname{det}([A]-\lambda \cdot[I])=0 \\
\left\{\begin{array}{c}
\left(\lambda+\frac{R}{L}\right)\left(\lambda-\frac{p}{C \cdot u_{c}^{2}}\right)+\frac{1}{L \cdot C}=0 \\
\lambda^{2}+\left(\frac{R}{L}-\frac{p}{C \cdot u_{c}^{2}}\right) \lambda+\frac{1}{L \cdot C}-\left(\frac{p \cdot R}{L \cdot C \cdot u_{c}^{2}}\right)=0
\end{array}\right.
\end{gathered}
$$

According to the theorem of Lyapunov stability, the system is stable if the real part of eigenvalues is always negative. In terms of average power $P$, this leads to the following conditions:

$$
P<\frac{R \cdot C}{L} U_{c}^{2}
$$

with $U_{c}$ the average value of $u_{c}(t)$.

Equation (7) is the stability condition of the system. If the dissipated power is larger than the limit value, the current will oscillate and be divergent, leading to an unstable system in comparison with a stable case (Fig. 2). In an unstable case, we can use the $\mathrm{AC}$ component of the current in order to create losses in the SS, which leads to an increase of the value of $R$ shown in (7). The SS has very low losses in superconducting state, i.e. with a DC component only, in a stable case. These losses can be considered as negligible in comparison with other losses in DC grid. Therefore, the value current $i(t)$ in a stable case, shall not exceed the critical current $I_{c}$ of the SS. But, in the unstable case, $i(t)$ must be higher than $I_{c}$ in order to create important losses in the SS. To obtain optimal results, the SS has to be designed with accuracy. The aim of this paper is to present the measurements of $I_{c}$ and the losses of the SS measured with AC + DC components of the current.

\section{Superconducting Stabilizer Design}

The SS used in this study is made from DI-BSCCO tape from Sumitomo, Fig. 4a. To allow compact SS with long length, DI-BSCCO tape is simply wound as a non-inductive coil such as in conventional Superconducting Resistive Fault Current Limiter [3]-[6]. Two superconducting non-inductive coils have been made. The first one is supported by an aluminium plate and fixed by resin (Fig. 4b) and the second is supported by wooden plate (Fig. 4c-c'). In this SS, the tape is free to move (Fig. 4c). The aluminium plate can create additional losses with the $\mathrm{AC}+\mathrm{DC}$ components in the unstable case. These additional losses can help to increase the stability margin in the DC grid. A comparison between a short length tape and the two superconducting non-inductive coils have been made in terms critical current and losses per unit length. This comparison allows us to know which design is the more suitable for SS.

The superconducting tape and the coils are described below:

- Tape: Sumitomo BSCCO Wire (DI-BSCCO) Type ACT [7]. The length between the two voltage tapes is: $L_{t a p s 1}$
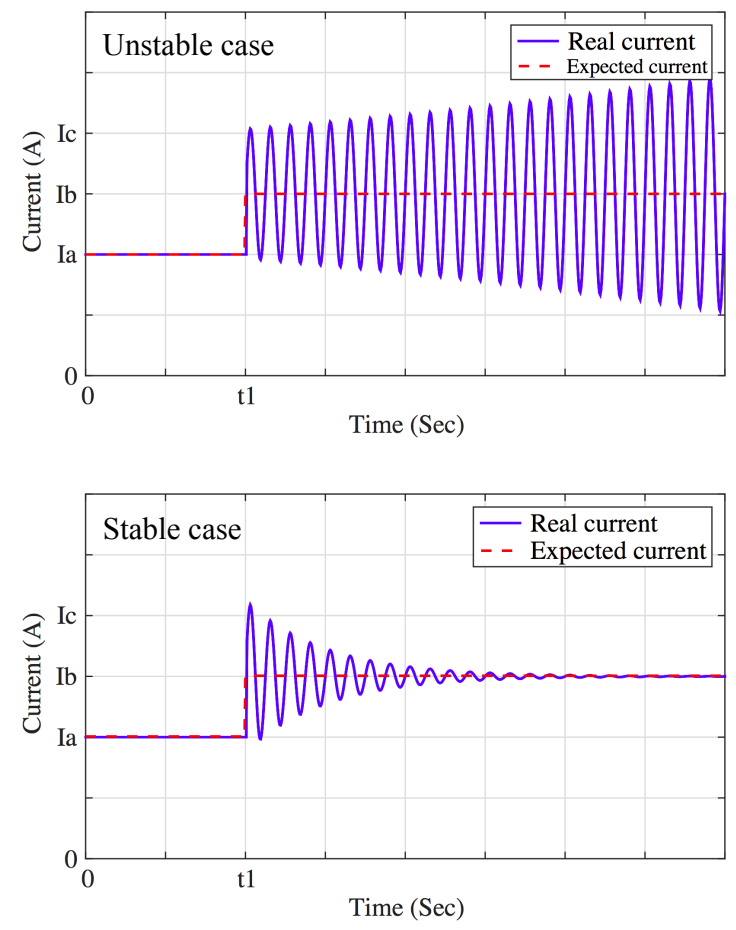

Fig. 2. Current in unstable case and in stable case

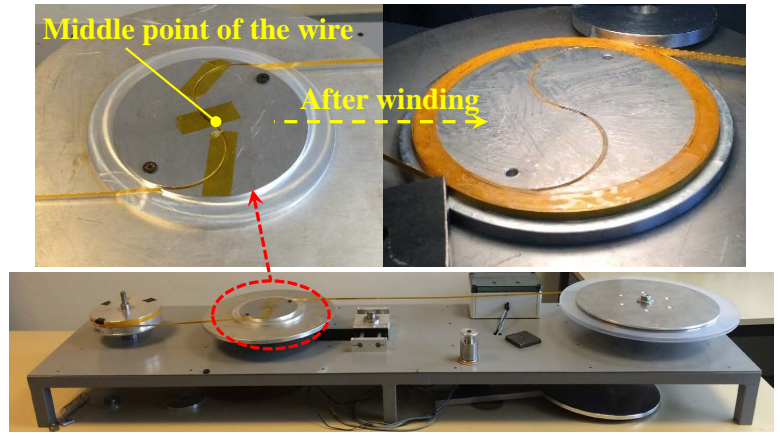

Fig. 3. Pictures of the manufacturing process of the non-inductive coils.

$=8 \mathrm{~cm}$. The HTS cross section is about $0.896 \mathrm{~mm}^{2}$, and Silver alloy represents more than $90 \%$ of the HTS cross section.

- Aluminium coil: winding by Tape, supported by an aluminium plate, voltage tapes of $L_{t a p s} 2=5.2 \mathrm{~m}$, the inside radius of plate $R_{2}=14 \mathrm{~cm}$, and the coil is impregnated with epoxy resin.

- Wooden coil: winding by Tape, supported by a wooden plate, voltage tapes of $L_{t a p s 3}=5 \mathrm{~m}$, inside radius of $R_{3}$ $=14 \mathrm{~cm}$, the turns are free to move and not impregnated.

\section{EXPERIMENTAL SETUP AND RESUlts}

\section{A. Experimental Setup}

The three prototypes are tested in three cases DC, AC and $\mathrm{DC}+\mathrm{AC}$. The experimental setup in $\mathrm{DC}, \mathrm{AC}$ and $\mathrm{DC}+\mathrm{AC}$ is shown in Fig. 5. In the DC case, the switch $K_{d c}$ is closed and the switch $K_{c d}$ is closed to the Nanovoltmeter. Other switches are opened. In the AC case, the switch $K_{a c}$ is closed and 


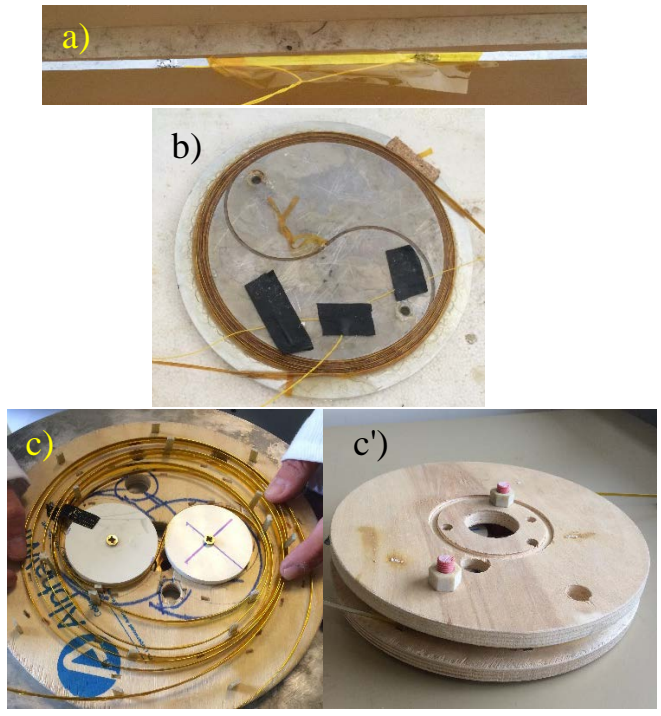

Fig. 4. (a) Pictures of the HTS tape, (b) the aluminium coil, and (c-c') the wooden coil.

the switch $K_{d c}$ is closed to the digital oscilloscope and the synchronous detection. The switch $K_{a b}$ is selected to measure the $\mathrm{AC}$ voltage or $\mathrm{AC}$ current. Other switches are opened. In the DC + AC case, $K_{d c}$ and $K_{a c}$ are closed at the same time, the switch $K_{d c}$ is need to stay at the same position in the AC case, the switch $K_{a b}$ is always selected as needed. In the DC test, we increase the DC current provided by a DC current supply and the voltage $U_{H T S}$ is measured by using a Nanovoltmeter. The electric field $E$ can be calculated by $E=$ $U_{H T S} / L_{\text {taps }}$, with $L_{\text {taps }}$ which represents the length between two electric potential taps. The critical current $I_{c}$ of the SS can be determined with the usual criterion of $1 \mu \mathrm{V} / \mathrm{cm}$. In the $\mathrm{AC}$ test, we use a standard method of $\mathrm{AC}$ losses measurements [8]-[9].

Then, at a given frequency, the maximum value of the AC transport current has been changed and the corresponding losses have been measured by mean of a synchronous detection. A digital oscilloscope is used, at the same time, in order to visualize whether the transport current is correctly sinusoidal.

When the electric grid is unstable, we have seen that the current presents $\mathrm{DC}+\mathrm{AC}$ components. In order to feed the SS by an DC + AC current, a DC current supply and an AC current supply have been installed in parallel with the SS. The shape of the corresponding current $i(t)$ is shown in Fig. 6. $I_{\max }$ is the maximum current that flows in the SS, its value is always two times the DC current part of $i(t)$.

\section{B. Results}

The DC case results are represented in Fig. 7. The short length tape and the two non-inductive coils have the same value of $I_{c}$. This proves that the effect of the magnetic field on the critical current created by the non-inductive coils is negligible. The value of $I_{c}$ is equal to $68 \mathrm{~A}$ for all the SS. Consequently, we can design and realize SS with very long length without differences compared to the single tape. In the $\mathrm{AC}$ case (Fig. 8), the AC losses per meter measured for the

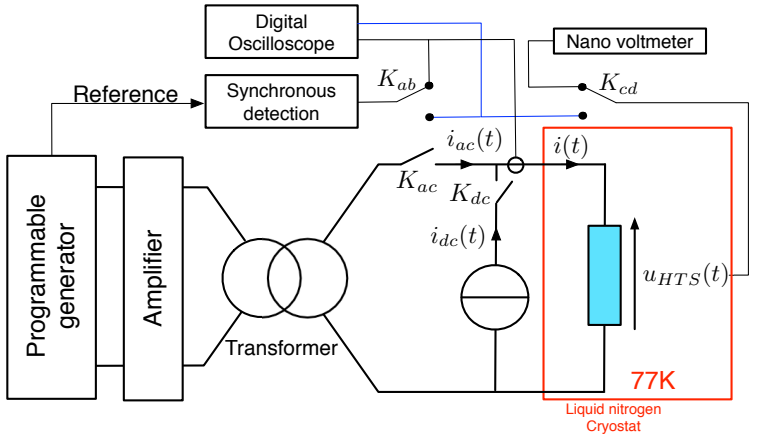

Fig. 5. Experimental setup in $\mathrm{DC}, \mathrm{AC}$ and $\mathrm{DC}+\mathrm{AC}$ cases.

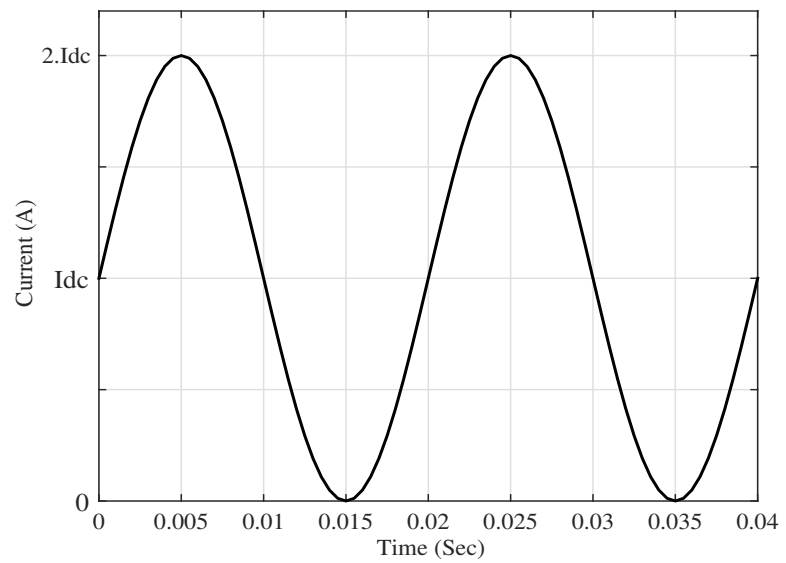

Fig. 6. Shape of the current $i(t)$ in the $\mathrm{DC}+\mathrm{AC}$ case.

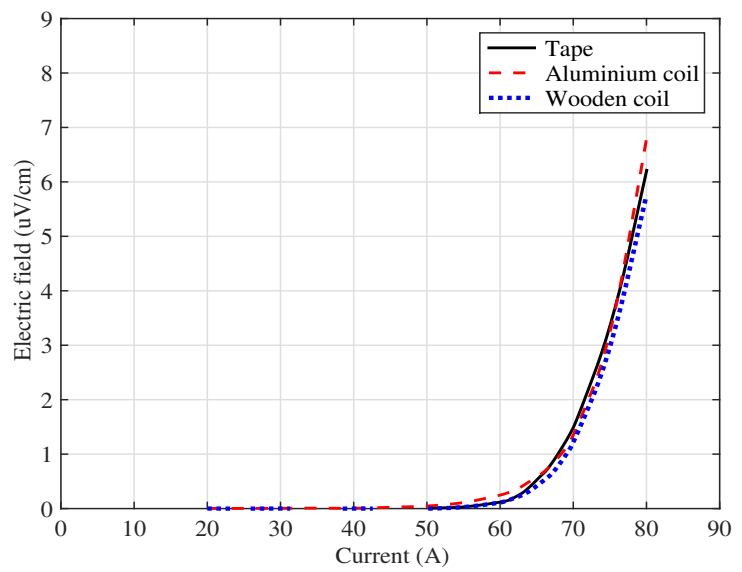

Fig. 7. Comparison of the electric field $E$ between the tape, the aluminium coil, and the wooden coil in the DC case. The value of $I_{c}$ is equal to $68 \mathrm{~A}$ for all the SS.

tape and the wooden coil are similar. The difference of the AC losses per meter between the two non-inductive coils can be explained by the losses in the aluminium plate. Indeed, eddy currents occur in the aluminium plate submitted to AC magnetic field.

In the $\mathrm{DC}+\mathrm{AC}$ case, the maximum current is always larger than $I_{c}$ of the SS because it corresponds to the operating conditions on a DC electric grid for which we want to design 


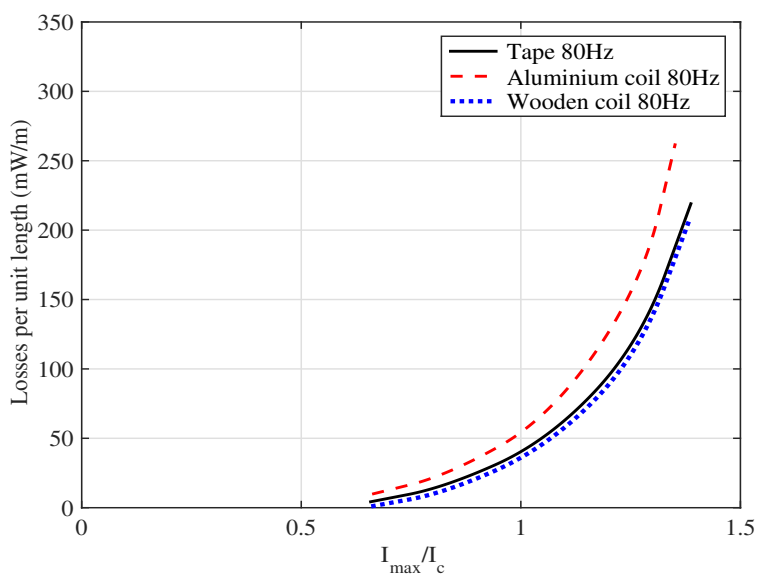

Fig. 8. Comparison of the AC losses per meter between the tape, the aluminium coil, and the wooden coil in the AC case.

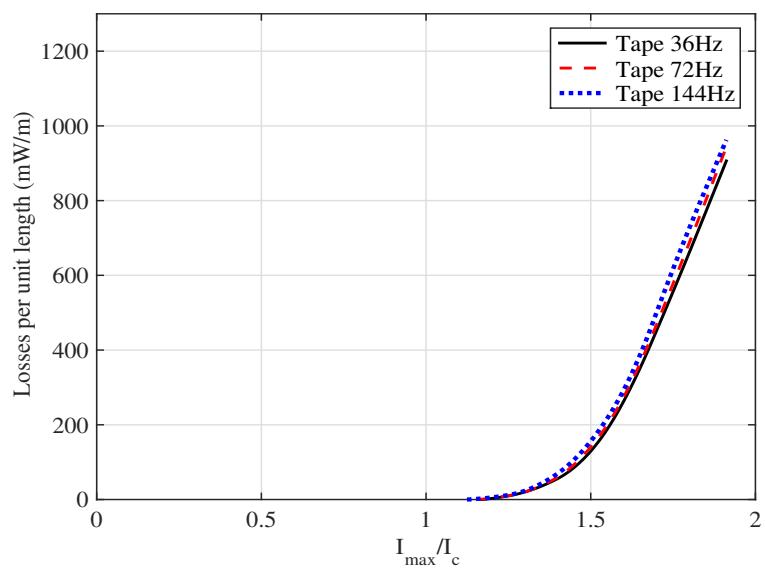

Fig. 9. $\mathrm{DC}+\mathrm{AC}$ losses per meter for the tape in the $\mathrm{DC}+\mathrm{AC}$ case for 3 different frequencies.

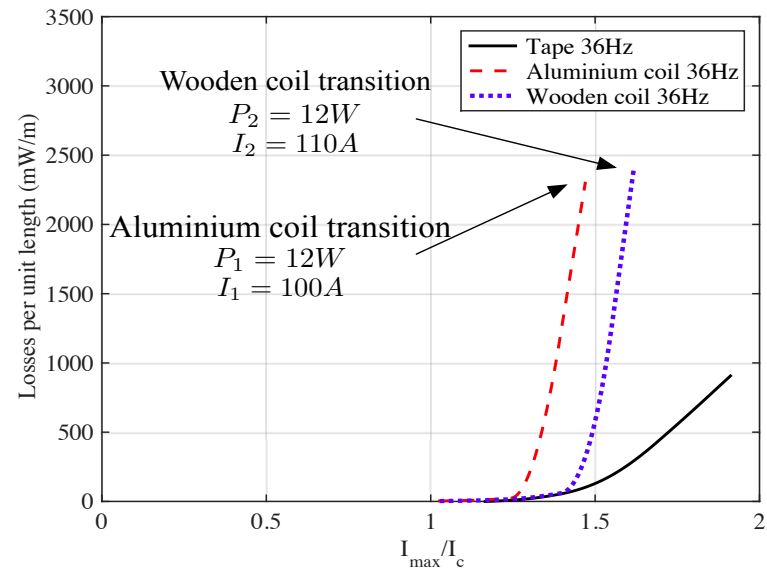

Fig. 10. Comparison of DC+AC losses per meter between the tape, the aluminium coil and the wooden coil in the $\mathrm{DC}+\mathrm{AC}$ case.

the SS. One can observe in Fig. 9 that the DC + AC losses per meter are frequency independent if the maximum current is larger than $I_{c}$. Indeed, in this configuration, losses are manly dominated by the resistive component of the losses in the HTS and not by hysteresis losses or induced losses. The comparison made in Fig. 10 shows the same DC + AC losses per meter for the three SS, before the transition of the aluminium coil and the wooden coil. These transitions were observed for a maximal current of $100 \mathrm{~A}$ and $110 \mathrm{~A}$, corresponding to $I_{\max } / I_{c}=1.47$ and 1.62 , respectively for the aluminium and the wooden coil. These transitions are due to thermal instabilities which depend on the cooling interfaces, here the exchanges with the liquid nitrogen bath and the turns. Although the wood is an isolating material, we believe that the cooling between turns is more effective in the wooden coil because the liquid Nitrogen can flow between the turns. When the current is larger than $I_{c}$, a short length tape can be cooled down easily contrariwise, the non-inductive coils cannot be cooled down easily. Therefore, the transition and the cooling of the coils should be taking into account in the design of future SS.

\section{Conclusion And Perspective}

In this paper, we present a new system based on a superconducting tape named Superconducting Stabilizer in order to stabilize DC electric grid. First, the demonstration of the stability condition in a given DC system was given. By using experimental means, we found the same value of critical current $I_{c}$ for a short length tape and two non-inductive coils. Moreover, almost the same AC and DC + AC losses per unit length for all the SS have been measured. The only and important observed difference is the maximal current which leads to the transition of the non-inductive coils. It can be explained by the cooling efficiency of the designed coils. These experimental results are useful to design SS in the future. A numerical thermal simulation and a test of the SS in a real electrical grid will be made in future works.

\section{REFERENCES}

[1] S.M. Blair, C.D. Booth, I.M. Elders, N.K. Singh, G.M. Burt, J. McCarthy, "Superconducting fault current limiter application in a power-dense marine electrical system", IET Electrical Systems in Transportation, vol. 1, Iss. 3, p. 93-102. 2011.

[2] I. Goldhirsch and Pierre-Louis Sulem and Steven A. Orszag, "Stability and Lyapunov stability of dynamical systems: A differential approach and a numerical method", Physica D: Nonlinear Phenomena, vol. 27, no. 3, pp. 311337, 1987.

[3] M. Noe and M. Steurer, High-temperature superconductor fault current limiters: concepts, applications, and development status, Superconductor Science and Technology, vol. 20, no. 3, p. R15, 2007.

[4] A. Morandi, State of the art of superconducting fault current limiters and their application to the electric power system, Physica C: Superconductivity, vol. 484, no. 0, pp. 242 247, 2013.

[5] A. Hobl, W. Goldacker, B. Dutoit, L. Martini, A. Petermann, and P. Tixador, Design and production of the eccoflow resistive fault current limiter, Applied Superconductivity, IEEE Transactions on, vol. 23, no. 3, pp. 56018045601804 , June 2013.

[6] C. Gandioli, P. Tixador, and G. Mariani, Tests and simulations of different ybco tapes for fcl, Applied Superconductivity, IEEE Transactions on, vol. 22, no. 3, pp. 56031045603 104, June 2012.

[7] Sumitomo BSCCO Wire (DI-BSCCO) Type ACT, [Online] Available : http://global-sei.com/super/hts_e/type_ac.html [Accessed : 04-Jan-2016].

[8] B. Douine, J. Leveque, and A. Rezzoug, "AC losses measurements of a high critical superconductor transporting sinusoidal or non sinusoidal current", Applied Superconductivity, IEEE Transactions on, vol. 10, no. 1, pp.1489-1492, 2000

[9] B. Douine, D. Netter, J. Leveque, A. Rezzoug, AC losses in a BSCCO current lead: comparison between calculation and measurement, Applied Superconductivity, IEEE Transactions on, vol. 12, n1, p. 1603-1606. 2002. 